\title{
Çocuk dişhekimliğinde lazerler
}

\section{Lasers in pediatric dentistry}

Fatih Öznurhan, DDS, PhD, ${ }^{a}$ Ayşegül Ölmez, DDS, $\mathrm{PhD}^{\mathrm{b}}$

${ }^{a}$ Cumhuriyet Üniversitesi, Diş Hekimliği Fakültesi, Pedodonti Anabilim Dalı, Sivas, Türkiye.

${ }^{\mathrm{b}}$ Gazi Üniversitesi, Diş Hekimliği Fakültesi, Pedodonti Anabilim Dalı, Ankara, Türkiye.

Received: 08 March 2011 Accepted: 17 June 2011

\section{ÖZET}

Konvansiyonel frez sistemi ile yapılan dental tedaviler vibrasyon, basınç, sürtünme, ssıya neden olur ve tüm bunlar korkuya neden olabilir. Lazerle yapılan tedaviler tüm bunları engelleyebilir. Diş tedavisi korkularını yenmek açısından lazer kullanımı çocuk diş hekimliğinde büyük bir avantajdır. Lazerler diş hekimliğinin pek çok farklı alanında kullanılmaktadır. Bu yayının amacı hem yumuşak ve sert dokuda kullanılan lazerlerin çocuk diş hekimliğinde kullanım alanlarının özetlenmesidir.

Anahtar Kelimeler: Çocuk Diş Hekimliği, Lazer

\section{GíRiș}

Light Amplification by Stimulated Emission of Radiation (Laser) radyasyonun uyarılmış yayılımı ile 1 şı şiddetinin arttırılmasıdır ve bu da ışığın uyarılarak güçlendirilmesi olarak tarif edilebilir. Bir ucu yansitıcı diğer ucu yarı yansitıcı olan iki aynaya sahip bir tüpün içine gaz, sivı veya gaz madde doldurulmuştur. $\mathrm{Bu}$ maddenin atomlarına bir enerji verilir ve verilen enerji atomlar tarafından emilir. Enerji fazla gelirse atomların foton yayması söz konusu olabilir. Yayılan bu fotonlar diğer fotonların yayılmasına neden olur ve aynalara ulaştıkça tüpün içinde sağa sola olmak üzere iki ayna üzerinde yansımaya başlarlar.

Fatih ÖZNURHAN

Cumhuriyet Üniversitesi

Diş hekimliği Fakültesi

Pedodonti AD Kampus/Sivas

Tel: 034621910 10-3103

Fax: 0 346.2191237

E-posta: foznurhan@cumhuriyet.edu.tr

\section{ABSTRACT}

Dental treatment with convantional bur system can cause vibration, pressure, friction, heat and these might eventually cause fear. Laser treatment may prevent all these negative outcome. The use of laser for overcoming dental fear and anxiety of children is a great advantage in paediatric dentistry. Lasers are used in a variety of dental treatments. The aim of this review is to summarize the use of lasers in pediatric dentistry that can be used at both soft and hard tissues.

Keywords: Pediatric Dentistry, Laser
Atomlarm her biri foton yaymaya başladığında kuvvetlenen fotonlar bir 1 şık demeti olarak yarı saydam uçtan çıkmaya başlar ve bu 1şı demetine de lazer denir. ${ }^{1-4}$

Lazerlerin diş hekimliğindeki kullanımı ise yumuşak dokular ve sert dokulardır. Diş hekimliğinde lazer çalıșmaları Thedore H. Maiman tarafından yapılmıştır. ${ }^{5}$ Goldman, Stern ve Sognnaes lazerin diş hekimliğinde kullanımını inceleyen ilk araştırmacılardır.

\section{Lazerin diş hekimliğine getirdiği avantajlar}

-Anesteziye daha az gereksinim olmasi ya da hiç olmaması

-Kanama kontrolü

-Dokularin kontrolü

-Frezlerin titreşimine bağlı olarak meydana gelen mikro-çatlakların önlenmesi

-Smear tabakasının oluşmaması, buna bağlı olarak asit uygulama işleminin gerekmemesi, sızıntı ve bakteri içermemesi 
-Doku iyileşmesinin çabuk olması

-Enfeksiyonun kontrolü

-Sessiz operasyon

-Titreşim ve basıncın olmaması

-Titreşim ve buna bağlı olarak gelişen ağrının önlenmesi

-Antibakteriyel etkisinin olmasıdır. ${ }^{7}$

\section{Lazerin diş hekimliğine getirdiği dezavantajlar}

-Bütün girişimler için tam olarak uygulanacak dalga boyunun dolayısıyla aletin bulunmamas1

-Bazı işlemlerde geleneksel yöntemlere oranla daha yavaş çalışması

-Operasyon sirasinda dokulara temas duygusunun olmamas 1

-Hedef bölgede 1sinın kontrol altına alınması gerekliliği

-Operasyon alanında minimum yansitıcı yüzey gereksinimi

-Operasyon ortamına girişin sınırlı olmas1

-Ortamda bulunan herkes için koruyucu gözlük gereksinimi

-Yüksek maliyetinin olmasıdır. ${ }^{7}$

Lazerler yumuşak ve sert dokuda farklı amaçlarla kullanılabilmektedir. Lazerler;

\section{Yumuşak dokularda}

-İnsizyonel ve eksizyonel biyopsileri içine alan oral yumuşak dokuların insizyonu, eksizyonu, vaporizasyonu, ablasyonu ve koagulasyonunda

-Yumuşak doku kesilmesi, flep kaldırılması ve kemiğe ulaşılmasında

-Kök kanal içeriğinin temizlenmesinde

-Pulpa ekstirpasyonunda

-Pulpatomide

-Sürmemiş dişlerin üzerinin açılmasında

-Fibroma çıkartılmasında

-Flep operasyonunda

-Frenotomi ve frenektomide

-Gingivektomi ve gingivoplastide

-Hemostazın sağlanmasında

-İmplantın çıkarılmasında

-İnsizyon ve abse drenajında

-Lökoplaki tedavisinde

-Operkuloktomide
-Oral papillektomide

-Gingival hiperplazi azaltılmasında

-Aftöz ülser tedavisinde

-Vestibüloplastide

-Sulküler debridmanın sağlanmasında

-Granülasyon

defektlerinin

uzaklaştırılmasında

-Yumuşak doku küretajında ${ }^{5,8}$

\section{Sert dokularda}

-Kavite preperasyonlarında (Sınıf I-VI)

ve giriş kavitesinin açılmasında

-Kök kanal preperasyonu ve genişletilmesinde

-Kemiğin kaldırılıp kök apeksine ulaşılmasında

-Kök ucu rezeksiyonunda

(amputasyonu)

-Kök ucunun kompozit yada amalgam restorasyon için hazırlanmasında

-Kök ucundaki patolojik dokuların uzaklaştırılmasında

-Mine, dentin, sement ve kemik gibi dokularda çürük temizlenmesinde

-Sert doku yüzeyinin pürüzlendirilmesi işleminde

-Pit ve fissürlerin örtücü için enameloplastisi ve ekskavasyonunda

-Asitlere karşı diş sert dokusunun direncini arttırıcı etkisi nedeniyle koruyucu diş hekimliğinde ve bu özelliği sebebiyle yeni oluşacak çürüklerin önlenmesinde

-Dentin kanallarını tıkama özelliği ile diş hassasiyeti tedavilerinde

-Bleaching (beyazlatma) tedavilerinde

-Oral kemik dokuların kesilmesi, tıraşlanması, kontur verilmesinde

-Osteoplasti ve osteotomide

-Kuron boyu

kullanılabilmektedir. ${ }^{5,8}$

\section{Çocuk diş hekimliğinde lazerlerin kullanımı}

Yumuşak ve sert dokularda kullanılan lazerler çocuk diş hekimliğinde birçok amaçla kullanılabilmektedir. Yumuşak dokularda ve sert dokularda farklı dalga boylarında farklı amaçlarla kullanımları bulunmaktadır. Geleneksel yöntemlerle yapılan tedavilerde aerötör kullanımındaki 
basınç, titreșim, ses gibi etkiler çocuk hastaları olumsuz etkilemektedir fakat lazerle yapılan tedavilerde bu olumsuz etkiler elimine edilebilmektedir. Birçok lazer sisteminde hasta aletin dişine temas ettiğini hissetmemekte ve bu nedenle konvansiyonel frez sistemindeki basınç, sürtünme, vibrasyon, aletin sesi gibi dezavantajlarından dolayı oluşabilecek korku, endişe ve ağrı hissi elimine edilmektedir. Lazerin kanal tedavisinde, antibakteriyel etkinliğinin olması, uygulama sonrası bakteri içermemesi, sızıntı gibi sonuçların olmaması ve hızlı çalışması diğer avantajları arasındadır. ${ }^{7,9-17}$ Sistemin bir diğer avantaj1 ise dentin yüzeyinde kalsiyum ve fosfor miktarını arttırması, asit ataklarına karşı daha azalmış çözünürlüğü olan bir yüzey oluşturması ve böylece diş yüzeyini koruyup çürük oluşumunu önlemesi şeklinde ifade edilmektedir. ${ }^{17}$

\section{Yumuşak doku lazerleri}

Yumuşak dokularda lazerler oral bölgedeki rahatsızlıkların uzaklaştırılması ve oral mukoza lezyonlarının tedavisindeki spesifik uygulamalarında kullanılmaktadır. Birçok yazar yumuşak dokulardaki lazer uygulamalarının çabuk ve kolay olduğu, anestezi kullanımının daha az olduğu ya da hiç olmadığı, insizyon boyunca kanama kontrolünün mükemmel olması, sütur gereksiniminin olmamas1, dekontaminasyon ve biyostimulasyon gibi etkilerinden dolayı postoperatif iyileşmenin asemptomatik olması konusunda hemfikirdir. Bununla birlikte hasta tarafından kabul edilebilirliği mükemmeldir ve geleneksel yöntemlerle karşılaştırıldığında operasyon sonrası antienflamatuar ve analjezik ilaç kullanımı daha azdır. ${ }^{18}$ Argon, diyot, karbondioksit $\left(\mathrm{CO}_{2}\right)$ türü lazerler yumuşak dokuda kesme, vaporizasyon ve dokunun dekontaminasyonunda etkilidir. İyi koagülasyon ve hemostaz sağlar ve vasküler lezyonlar için idealdirler. Erbium, chromium: yttrium, scandium, gallium, garnet (Er,Cr:YSGG) ve Erbium: yttriumaluminum-garnet (Er:YAG) lazerleri bu uygulamalarda etkilidir fakat kanama kontrolü daha azdır. Ayrıca erbiyum lazerleri periferalde nekrotik alan bırakmadan, yumuşak dokuda limitli bir 1s1 artışı yaparak düzgün bir kesim ve vaporizasyon alanı oluşturur. ${ }^{19,20}$ Yumuşak dokuda lazer kullanımı sonrasinda yara kenarları birleştiği için sütur, periyodontal pat ve bandaj kullanıma gerek kalmaz. ${ }^{21}$

\section{Yumuşak doku lazerleri ile klinik uygulamalar}

Lazerlerin klinik uygulamaları yetişkin hastalarda birçok alanda kullanılmakta etkinliğinin kanıtlanmasına karşın çocuk hastalarda bulunan vaka sayısı sinırlıdır. Herpes lezyonları, aft, hemanjiyom, fibrom, papillom, epulis, piyojenik granülom, mukosel, erupsiyon kisti, dentigeröz kist gibi hastalıkların tedavisinde uygulaması kolay, güvenli ve hızlıdır. En fazla kullanılan uygulama ise frenektomilerdir. Birçok yazar diyot, Neodymium: yttrium-aluminumgarnet (Nd:YAG), Er,Cr:YSGG ve Er:YAG ve $\mathrm{CO}_{2}$ lazer uygulamalarının operasyon sonrasında daha az ağrı, rahatsızlık ve fonksiyonel komplikasyonların oluşturduğunu ve böylece hasta uyumunun daha iyi olduğunu bildirmişlerdir. Yeni doğanda ankiloglossi, yada frenilum gibi durumlar da bebeğin anne sütünü alması daha güç olduğundan bu tür uygulamalar basit ve etkilidir. ${ }^{22,23}$ Gingivektomi, gingivoplasti ve operkulektomi gibi işlemler anestezi gerektirmeden tamamlanabilmektedir. Bununla birlikte ortodontik hareketlerde oluşan ağrilarda biyositumülasyon etkilerinin pozitif etkileri görülebilmektedir. ${ }^{24-26}$

\section{Sert doku lazerleri}

Yumuşak dokuda kullanılan birçok lazer sert dokularda da uygulanmış fakat etkisi sınırlı kalmış ve istenilen etkiyi göstermemişlerdir. Daha önceki lazerlerin kullanımında sert dokuları buharlaştırma, eritmede etkin olmamaları, karbonizasyon görülmesi, çevre dokularda çatlak ve fissür oluşturmaları, pulpa dokusunda 1S1 artış1 gibi büyük yan etkiler görülmüştür. Bu tip 
yan etkilerin görülmediği bir lazer sistemi ihtiyaç haline gelmiştir. ${ }^{11}$

Sert doku lazerleri yüksek enerjiye sahip lazerlerdir. Enerji açığa çıkardıkları için termik lazer olarak da adlandırılırlar. $\mathrm{Bu}$ grupta Argon, $\mathrm{CO}_{2}$ ve yttriumaluminum-garnet (YAG) lazerleri saymak mümkündür. Kompozit rezinlerin polimerizasyonu, sert doku preparasyonları, çürükten korunma, çürük teşhis ve uzaklaştırılmasında, pulpa kaplaması, pulpotomi, kök kanal içeriğinin dezenfeksiyonu ve kök düzeltilmesinde kullanılabilmektedir. ${ }^{6}$

Lazer ile yapılan süt dişi çalışmaları sınırlı sayıdadır. Yapılan bu çalışmalarda kullanılan lazerlerde süt dişlerinde ağrı oluşturmadığı, dentin dokusunda karbonizasyon, smear tabakası oluşturmadığı, dentin tübüllerinin ekspoze olduğu, yaptığı yüzey pürüzlendirmesinin yeterli olduğu bildirilmiştir. ${ }^{11-14,27}$ Kullanılan lazerlerin turlu sistemler gibi 1s1, ses, basınç, titreşim, ağrı oluşturmaması, smear tabakası oluşturmaması ve pürüzlendirme etkinliğinin olması çocuk diş hekimliğinde büyük bir avantaj oluşturmaktadır. ${ }^{11}$

\section{Sert doku lazerleri ile klinik uygulamalar}

Yapılan çalışmalarda lazerin mine, dentin, sement ve kemik dokular üzerinde güvenli kullanımı olduğu, çürügün etkin bir şekilde temizlenebildiği, konvansiyonel frez sistemine göre daha az ses oluşturduğu, basinç ve pulpal dokuda 1sı artış1 oluşturmadığ 1 ve böylece çocuk hastalarda kullanımında ağrı oluşturmadığ1 bildirilmiştir. Bununla birlikte ağrının elimine edilmesi için anesteziklerin kullanımından kaçınıldığı ve bunların yan etkilerinden ve anestezi sirasinda ve sonrasında oluşabilecek komplikasyonlardan kaçınılmış olunacağı, geleneksel ekskavatör, çelik frez ve aerötör kullanımındaki ses, titreşim, basınç gibi etkilerin ortadan kaldırılacağı fakat tüm bunlarla birlikte işlemin geleneksel yöntemlere oranla daha uzun sürdüğü bildirilmektedir. $^{13,14}$ Çeşitli araştırma ve vaka raporlarına bakıldığında lazerin çocuk diş hekimliğinde geleneksel yönteme karşı güvenli bir alternatif olabileceğ ${ }^{28}$ ve çocuk tarafından daha kolay kabul edilebileceği bildirilmektedir ${ }^{29-31}$

\section{Lazerler ile yapılan çalıșmalar}

\section{Çürük tespiti ve yüzey çalışmaları}

Çürük teşhisinde birçok metot kullanılmaktadır. $\mathrm{Bu}$ metotlara ek olarak $655 \mathrm{~nm}$ deki görülebilir kırmızı spektrumdaki lazer floresans (LF) kullanılabilmektedir. LF, okluzal ve proksimal çürük teşhisinde ek olarak kullanılabileceğini bildirmiştir. $^{32}$ LF ile yapılan birçok çalışma mevcuttur. Yapılan çalışmalarda araştırmacıların bir kısmı LF yönteminin diğer metotlara göre daha iyi olduğunu bildirirken ${ }^{33-35}$, bir grup araştırmacı diğer metotlarla eşdeğer olduğunu ve diğer bir grupsa ortam faktörlerine ve uygulayıcıya göre değişkenlik gösterebildiğini bildirmektedir. ${ }^{32,36,37}$

Yapılan birçok çalışmada lazerle birlikte fluorid kullanımının diş çürüklerine karşı direnci arttırdığ 1 bildirilmiştir.

Westerman ve $\operatorname{ark}^{38}$ yaptıkları bir çalışmada lazer uygulaması sonrasında mine yüzey mikro sertliğinin kontrol grubuna oranla daha sert olduğu bildirilmiştir. Bununla birlikte $\mathrm{CO}_{2}$ lazer uygulamasının mine yüzeyindeki demineralizasyonu azalttığ birlikte yapılacak yüksek oranda fluorid uygulamasının bu etkiyi arttırdığı bildirilmiştir. ${ }^{39}$ Yapılan bir diğer çalışmada kullanılan Er,Cr:YSGG lazerin asitlere karşı direnci $\operatorname{arttırdığ~} 1$ ve mine çözünürlüğünü azalttığı bildirilmiştir. ${ }^{40}$

\section{Mine ve Dentin}

Lazerin kullanıldı ̆̆ 1 bir diğer alan mine ve dentin dokusudur. Mine ve dentin dokusunda pürüzlendirme etkinliği, bağlanma kuvvetleri ve sızıntı üzerine birçok çalışma yapılmıştır. 
Lazer sistemlerinin bir avantajı da diş yüzeyinde oluşan smear tabakasını elimine etmesi ve pürüzlendirme etkinliği oluşturmasıdır. Yapılan çalışmalarda lazer sisteminin kavite preperasyonu sirasinda smear tabakası oluşturmadığ yüzeylerinde çatlak oluşturmadan ve dokuya zarar vermeden pürüzlendirme sağladığ bildirilmiştir. $^{17,41}$ Lazerin sağladığ 1 bu pürüzlendirme etkisinin asitle pürüzlendirmeye karş1 bir alternatif olabileceği bildirilmiştir. ${ }^{11,17,42-44} \mathrm{Bu}$ etki ile restorasyon işlemi sırasında asitle pürüzlendirme basamağını elimine edileceği ve bu eliminasyonun çocuk hastada tedavi süresini kisaltacağı düşünülmektedir.

Yapılan diğer çalışmalarda bağlanma kuvveti, mikrosızıntı değerleri lazer kullanılarak, invaziv yöntemler asitle pürüzlendirme yapılarak ve yapılmaksızın karşılaştırılmış ve aralarında anlamlı bir fark bulunamamıştır.

Youssef ve $\operatorname{ark}^{45}$ yaptıkları bir çalışmada asitle pürüzlendirme uygulandığında her iki tipteki mine yüzeyi hazırlanmasında bir fark bulamazken sadece Er:YAG lazer uygulamasinda en fazla sızıntı olduğunu bildirmișlerdir.

Bununla birlikte Moshonov ve $\operatorname{ark}^{46}$ yaptıkları bir çalışmada lazer ve asitle pürüzlendirme arasında bir fark olmadığını ve yöntemin etkili olabileceğini bildirmişlerdir.

Er,Cr:YSGG lazer sistemi ile yapılan çalışmalarda ise Çehreli ve $\operatorname{ark}^{47}$ Er,Cr:YSGG lazer ile hazırlanan süt dişlerinin oklüzal yüzeylerindeki fissür örtücülerin bağlanmasının mikrosızıntısını değerlendirmişlerdir. Er,Cr:YSGG lazer ile hazırlanan süt dişi örneklerinin sızıntısının asitle pürüzlendirilen örneklerle eşdeğer olduğunu ve asitle pürüzlendirme yerine kullanılabileceğini bildirmişlerdir. Tüm bu sonuçlar değerlendirildiğinde lazerle birlikte asitle pürüzlendirme yapılan tedavilerin daha başarılı olduğu bildirilmekte ve tavsiye edilmektedir.

\section{Kompozit adezyonu ve sizint çalışmaları}

Yapılan çalışmalarda lazer uygulanmış yüzeylerde kompozit adezyon sorusu tartışmalıdır. Bu konuda birçok araştırmacı yaptıkları çalışmalarda farklı farklı görüşler bildirmişlerdir.

Hossain ve $\operatorname{ark}^{12}$ süt dişlerinde frez ve lazer ile kavite hazırlanması sonrasında kompozit rezin restorasyonların sızıntısını incelemişler ve sonuç olarak kavite yüzeylerinin rezin restorasyon için iyi bir adezyon gösterdiğini ve asitle pürüzlendirme basamağının atlatılabileceğini bildirmişlerdir.

Hossain ve $\operatorname{ark}^{48}$, Moshonov ve $\operatorname{ark}^{46}$, Görgül ve $\operatorname{ark}^{49}$, Quo ve $\operatorname{ark}^{50}$, Ceballos ve $\operatorname{ark}^{51}$, Aranha ve $\operatorname{ark}^{52}$, Delme ve $\operatorname{ark}^{53}$ ve Arısu ve $\operatorname{ark}^{54} \mathrm{Nd}: Y A G$ ve Er:YAG lazerler ile hazırlanan kavitelerdeki pürüzlendirme etkisinin ve mikrosızıntısını karşılaştırdıkları çalışmalarında, her iki grupta da lazer ve frez ile hazırlanan kavitelerdeki pürüzlendirme etkisi ve mikrosızıntı açısından bir fark oluşmadığını bildirmişlerdir.

Bununla birlikte, Gutknecht ve $\operatorname{ark}^{44}$, Er,Cr:YSGG lazer, lazer sonrası asitle pürüzlendirme ve frez ile hazırlanan sınıf II kavitelerde kompozit dolguların sızıntısını araştırdıkları çalışmalarında, gruplar arasında istatistiksel olarak fark bulunmadığını fakat Er,Cr:YSGG lazer grubunda daha fazla boyanma olduğunu bildirmişlerdir. Sonuç olarak Er,Cr:YSGG lazerle hazırlanan kavitelerde asitle pürüzlendirme işlemi yapılmasını tavsiye etmişlerdir.

Armengol ve $\operatorname{ark}^{55}$ Er:YAG lazer, Neodymium: Yttrium, Aluminium, Pevroskite (Nd:YAP) lazer ve frez+asitle pürüzlendirme ile hazırlanan sinıf $\mathrm{V}$ kavitelerdeki kompozit restorasyonların sızıntı değerlerini araştırmışlar ve her iki lazerle hazırlanan kavitelerin iyi bir tıkama sağlamadığı ve frez+asitle pürüzlendirme grubunun ortalama sızıntı değerlerinin altında bulunduğunu bildirmişlerdir.

Corona ve $\operatorname{ark}^{56}$ Er:YAG lazer ve konvansiyonel frez sisteminin farklı sinıf 
V kavitelerdeki restorasyonların sızıntısını değerlendirdikleri çalışmalarında, restoratif materyale bağlı olarak Er:YAG lazer ile hazırlanan kavitelerin daha fazla sızıntı gösterdiğini bildirmişlerdir.

Youssef ve $\operatorname{ark}^{45}$ yüksek turlu el aleti ve Er:YAG lazer ile hazırlanan minede fissür örtücü olarak akışkan kompozit rezin kullanıldığında in vitro olarak marjinal mikrosızıntıyı değerlendirmişlerdir. Asitle pürüzlendirme yapılan gruplarda sızıntı değerlendirildiğinde istatistiksel olarak bir fark olmadığını fakat sadece Er:YAG lazer kullanıldığında sızıntı değerlerinin daha fazla olduğunu bildirmişlerdir.

Roebuck ve $\operatorname{ark}^{57}$ sinif V kompomer rezin restorasyonlarda Er:YAG lazerin üç farklı 1şınlama seviyesini kullanarak sızıntısını incelemişler ve tüm gruplarda hem dentin hem de mine seviyesinde sızıntı olduğunu bildirmişlerdir.

Ergücü ve $\operatorname{ark}^{58} \mathrm{Er}, \mathrm{Cr}$ :YSGG ve frez ile hazırlanan sinıf $\mathrm{V}$ kavitelerdeki kompozit rezin restorasyonların sizıntısinı inceledikleri bir çalışmada, lazer uygulanması ardından asitle pürüzlendirme yapılan grupta daha az sızıntı olduğunu bildirmişler ve Er,Cr:YSGG lazer uygulanması ardından asitle pürüzlendirme işlemini tavsiye etmişlerdir.

Yukarıda yapılan birçok çalışma 1şığında lazer ile yapılan pürüzlendirmenin tek başına yeterli olmadığ ve lazer uygulanması sonrasinda asitle pürüzlendirme yapılması tavsiye edilmektedir.

\section{Lazer ve endodonti}

Lazer erişkin hastaların endodontik uygulamalarında birçok kez kullanılmış fakat çocuk hastalarda yapılan çalışma sayısı sınırlıdır. Çocuk hastada pulpa kaplamalarında, pulpotomide, kök kanal içeriğinin temizlenmesinde ve disenfeksiyonunda kullanılabilmektedir.

Yamazaki ve $\operatorname{ark}^{59}$, Chen ${ }^{60}$, Soares ve $\operatorname{ark}^{61}$, Jahan ve $\operatorname{ark}^{62}$, Shoop ve $\operatorname{ark}^{63}$ lazerin kök kanal tedavisinde kullanımının etkinliğini değerlendirdikleri çalışmalarında, lazerin su soğutması ile birlikte kullanımda kök kanal duvarlarında smear tabakası ve debris uzaklaştırmada etkin olduğunu, kök kanal içeriğinin temizlendiğini ve antibakteriyel olduğunu bildirmişlerdir.

Santucci $^{64}$ ve Moritz ${ }^{3}$ yaptıkları pulpa kaplaması çalışmalarında lazer kullanımında yüksek oranlarda başarı olduğunu bildirmişlerdir. İki lazer sistemi ve kalsiyum hidroksitin karşılaştırıldığ bir çalışmada en fazla başarı oranını Er,Cr:YSGG lazerde \%80, Er:YAG lazerde $\% 75$ ve kalsiyum hidroksitte $\% 63$ olduğunu bildirilmiştir. ${ }^{19}$

Çocuk hastada bir diğer kullanım ise pulpatomidir. Süt dişi pulpatomi tedavilerinde formokrezolun 1:5 lik dilusyonu yaygın ve başarılı bir şekilde kullanılmaktadır fakat formokrezolun mutajenik ve karsinojenik olduğu düşünülmesi ile birlikte alternatif yöntemler araştırılmaktadır. $\mathrm{Bu}$ yüzden lazerlerin bu yönteme alternatif olabileceği önerilmiştir. Elliott ${ }^{65}$ ve Odabaş ${ }^{66}$ yaptıkları pulpatomi çalışmalarında lazer uygulanan grupların daha başarılı olduğunu bildirmişlerdir.

Lazerlerin, kök kanal tedavisinde el ile yapilan enstrumantasyon ve rotary sistemlerine oranla daha kisa sürede kök kanal içeriğinin temizlenmesinin ve kanalın şekillendirilmesini yaptığ bildirilmektedir. ${ }^{61}$

Lazerlerin tüm bu özelliklerinin dışında biyostimülasyon ve ağrı kontrolünde ve dental yaralanmalarda kullanımını bildiren araştırmalar bulunmaktadır.

Dental travmalarda hem yumuşak hem de sert doku etkilendiği için lazerler bu bölgelerde kullanılabilmektedir. Travma etkilediği bölgede hem mine hem dentini içine alan kırıklara sebep olabilir. $\mathrm{Bu}$ tip vakalarda hassasiyet gidermek amaciyla, pulpa kaplamasında, pulpatomide, kök kanal tedavisinde, yüzey pürüzlendirmede, gingival düzeltmelerde, dişeti insizyonunda ve avulsuyon sonrası alveol soketin dekontaminasyonunda kullanılabilmektedir.

Hem yumuşak hem sert dokuda düşük seviyede lazer uygulamaları yapılabilir. 
Lezyonların biyostimülasyonunda, aftöz stomatitlerde, herpetik lezyonlarda, mukozitlerde, pulpatomide, aljezi, ortodontik ağrılarda, operasyon sonrası ağrılarda ve temporamandibular eklem ağrılarında kullanılabilmektedir. Çocuk diş hekimliğinde düşük seviyeli lazer uygulamalarının beş ana endikasyonu olduğunu bildirilmiştir.

-Süt ve daimi dişlerin erüpsiyonu bazen ağrılıdır. Bu bölgelerdeki lenf nodlarının 1şınlanması bu ağrıların için tavsiye edilebilir.

-Mukozaya yapılan 2J'lük düşük dozdaki ışınlama, enjeksiyon yapılırkenki iğne ağrısını dindirebilir.

-Süt dişlerinde kavite üzerine yapılan 46J'lük 1şınlama ağrı kontrolünde kullanılabilir

-Travma sonrasında 3-4J'lük ışınlama dudak ve ön dişler bölgesinde oluşabilecek şişliklerin azaltılmasında kullanılabilir

-Pulpa kaplamalarında 1-2J'lük kullanımı tedavideki başarı oranını artırmaktadır. ${ }^{18}$

\section{SONUÇ}

Diş hekimliğinde lazer kullanımı her geçen gün yaygınlaşmaktadır. Gerek sert doku gerekse yumuşak doku uygulamalarında birçok alanda kullanılan lazerler çocuk diş hekimliğinde de kullanılabilmektedir. Diş hekimliğinde birçok alanda kullanılabilen lazerler geleneksel aeratör kullanımı ile gündeme gelen basınç, titreşim, ses gibi etkileri elimine etmektedir. Lazer sisteminde çocuk hasta, aletin dişine temas ettiğini hissetmemekte ve bu nedenle konvansiyonel frez sistemindeki basınç, sürtünme, vibrasyon, aletin sesi, 1s1 gibi dezavantajlarından dolayı oluşabilecek korku, endişe ve ağrı hissi ortadan kalkmakta, operasyon sonrası ağrı daha az oluşmakta ve iyileşme süresi daha kısa sürmektedir. ${ }^{9-11,13-16,67-69}$ Yumuşak dokuda kullanılan lazerler benzer teknoloji ve benzer uygulama protokolleri ile gerek hasta uyumu, gerekse de operasyon sirası ve sonrası oluşabilecek komplikasyonların azlığ1 sebebiyle çocuk hastalar için idealdir. Sert doku uygulamalarında daha çok erbiyum grubu lazerler kullanılmaktadır. Her iki lazerin farklı dalga boylarının olmasi, hedef dokuda farklı 1şınlama süreleri, hava/su oranlarının farklılı $\breve{g}_{1}$ ve diğer parametreleri lazerlerin dokulardaki etkileşimini etkilemektedir. Aynı grupta sayılmalarına rağmen her iki lazeri bu gibi sebeplerden dolay1 karşılaştırılamazlar. Çocuk hastalarda kullanımlarında gerek sert dokuda gerek yumuşak dokuda kullanılan bu lazerler doğru enerji ile uygulandıklarında çocuk hastaların en büyük korkusu olan sürtünme, titreşim, basınç ve 1sı ile ortaya çıkan ağrıları ortadan kaldıracak hasta uyumu ve diş hekimi fobisini yenecektir.

\section{KAYNAKLAR}

1. Coluzzi DJ. An overview of laser wavelengths used in dentistry. Dent Clin North Am 2000;44(4):753-765.

2. Moritz A, Schoop U, Goharkhay K, Sperr W. The CO2 laser as an aid in direct pulp capping. J Endod 1998;24(4):248-251. [CrossRef]

3. Moritz A, Schoop U, Goharkhay K, Sperr W. Advantages of a pulsed $\mathrm{CO} 2$ laser in direct pulp capping: a long-term in vivo study. Lasers Surg Med 1998;22(5):288-293. [CrossRef]

4. Sulewski JG. Historical survey of laser dentistry. Dent Clin North Am 2000;44(4):717-752.

5. Dederich DN, Bushick RD. Lasers in dentistry: separating science from hype. J Am Dent Assoc 2004;135(2):204-212; quiz 229.

6. Altundaşar E. Kök Kanallarında Er,Cr:YSGG Lazer Kullanımının, Dentinin Mineral İçeriğine Etkisi ve Smear Tabakasını Uzaklaştırma Etkinliğinin Araştırılması [Doktora Tezi]. Ankara: Hacettepe Üniversitesi. 2006.

7. Akgün B. Diş Hekimliğinde Lazer. Dentalife 2004;9:14-19.

8. Walsh LJ. The current status of laser applications in dentistry. Aust Dent $\mathbf{J}$ 


\section{3;48(3):146-155; quiz 198. [CrossRef]}

9. Hadley J, Young DA, Eversole LR, Gornbein JA. A laser-powered hydrokinetic system for caries removal and cavity preparation. J Am Dent Assoc 2000;131(6):777-785.

10. Hossain M, Nakamura Y, Tamaki Y, Yamada Y, Murakami Y, Matsumoto $\mathrm{K}$. Atomic analysis and knoop hardness measurement of the cavity floor prepared by Er,Cr:YSGG laser irradiation in vitro. J Oral Rehabil 2003;30(5):515-521. [CrossRef]

11. Hossain $M$, Nakamura $Y$, Yamada $Y$, Murakami Y, Matsumoto K. Compositional and structural changes of human dentin following caries removal by Er,Cr:YSGG laser irradiation in primary teeth. J Clin Pediatr Dent 2002;26(4):377-382.

12. Hossain $M$, Nakamura $Y$, Yamada $Y$, Murakami Y, Matsumoto K. Microleakage of composite resin restoration in cavities prepared by Er,Cr:YSGG laser irradiation and etched bur cavities in primary teeth. $\mathrm{J}$ Clin Pediatr Dent 2002;26(3):263268.

13. Jacboson B, Berger J, Kravitz R, Ko J. Laser pediatric Class II composites utilizing no anesthesia. J Clin Pediatr Dent 2004;28(2):99-101.

14. Jacboson B, Berger J, Kravitz R, Patel P. Laser pediatric crowns performed without anesthesia: a contemporary technique. J Clin Pediatr Dent 2003;28(1):11-12.

15. Lin S, Caputo AA, Eversole LR, Rizoiu I. Topographical characteristics and shear bond strength of tooth surfaces cut with a laser-powered hydrokinetic system. J Prosthet Dent 1999;82(4):451-455. [CrossRef]

16. Rizoiu IM, Eversole LR, Kimmel AI. Effects of an erbium, chromium: yttrium, scandium, gallium, garnet laser on mucocutanous soft tissues. Oral Surg Oral Med Oral Pathol Oral
Radiol Endod 1996;82(4):386-395. [CrossRef]

17. Usumez A, Aykent F. Bond strengths of porcelain laminate veneers to tooth surfaces prepared with acid and Er,Cr:YSGG laser etching. J Prosthet Dent 2003;90(1):24-30. [CrossRef]

18. Olivi G, Genovese MD, Caprioglio C. Evidence-based dentistry on laser paediatric dentistry: review and outlook. Eur J Paediatr Dent 2009;10(1):29-40.

19. Olivi G, Genovese MD, Maturo P, Docimo R. Pulp capping: advantages of using laser technology. Eur J Paediatr Dent 2007;8(2):89-95.

20. Boj JR, Hernandez M, Espasa E, Poirier C. Laser treatment of an oral papilloma in the pediatric dental office: a case report. Quintessence Int 2007;38(4):307-312.

21. Myers TD, McDaniel JD. The pulsed $\mathrm{Nd}$ :YAG dental laser: review of clinical applications. J Calif Dent Assoc 1991;19(11):25-30.

22. Haytac MC, Ozcelik O. Evaluation of patient perceptions after frenectomy operations: a comparison of carbon dioxide laser and scalpel techniques. J Periodontol 2006;77(11):18151819. [CrossRef]

23. Kara C. Evaluation of patient perceptions of frenectomy: a comparison of $\mathrm{Nd}$ :YAG laser and conventional techniques. Photomed Laser Surg 2008;26(2):147-152. [CrossRef]

24. Cruz DR, Kohara EK, Ribeiro MS, Wetter NU. Effects of low-intensity laser therapy on the orthodontic movement velocity of human teeth: a preliminary study. Lasers Surg Med 2004;35(2):117-120. [CrossRef]

25. Youssef M, Ashkar S, Hamade E, Gutknecht N, Lampert F, Mir M. The effect of low-level laser therapy during orthodontic movement: a preliminary study. Lasers Med Sci 2008;23(1):27-33. [CrossRef] 
26. Pretel H, Lizarelli RF, Ramalho LT. Effect of low-level laser therapy on bone repair: histological study in rats. Lasers Surg Med 2007;39(10):788796. [CrossRef]

27. Sung EC, Chenard T, Caputo AA, Amodeo M, Chung EM, Rizoiu IM. Composite resin bond strength to primary dentin prepared with Er, Cr:YSSG laser. J Clin Pediatr Dent 2005;30(1):45-49.

28. Kornblit R, Trapani D, Bossu M, Muller-Bolla M, Rocca JP, Polimeni A. The use of Erbium:YAG laser for caries removal in paediatric patients following Minimally Invasive Dentistry concepts. Eur J Paediatr Dent 2008;9(2):81-87.

29. Keller U, Hibst R, Geurtsen W, Schilke R, Heidemann D, Klaiber B, Raab WH. Erbium:YAG laser application in caries therapy. Evaluation of patient perception and acceptance. J Dent 1998;26(8):649656. [CrossRef]

30. Liu JF, Lai YL, Shu WY, Lee SY. Acceptance and efficiency of Er:YAG laser for cavity preparation in children. Photomed Laser Surg 2006;24(4):489-493. [CrossRef]

31. Takamori K, Furukawa H, Morikawa Y, Katayama T, Watanabe S. Basic study on vibrations during tooth preparations caused by high-speed drilling and Er:YAG laser irradiation. Lasers Surg Med 2003;32(1):25-31. [CrossRef]

32. Lussi A, Zimmerli B, Hellwig E, Jaeggi $T$. Influence of the condition of the adjacent tooth surface on fluorescence measurements for the detection of approximal caries. Eur J Oral Sci 2006;114(6):478-482. [CrossRef]

33. Burin $C$, Burin $C$, Loguercio $A D$, Grande RH, Reis A. Occlusal caries detection: a comparison of a laser fluorescence system and conventional methods. Pediatr Dent 2005;27(4):307-312.
34. Mendes FM, Ganzerla E, Nunes AF, Puig AV, Imparato JC. Use of highpowered magnification to detect occlusal caries in primary teeth. Am J Dent 2006;19(1):19-22.

35. Barberia E, Maroto $M$, Arenas $M$, Silva CC. A clinical study of caries diagnosis with a laser fluorescence system. J Am Dent Assoc 2008;139(5):572-579.

36. Bengtson AL, Gomes AC, Mendes FM, Cichello LR, Bengtson NG, Pinheiro SL. Influence of examiner's clinical experience in detecting occlusal caries lesions in primary teeth. Pediatr Dent 2005;27(3):238243.

37. Olmez A, Tuna D, Oznurhan F. Clinical evaluation of diagnodent in detection of occlusal caries in children. J Clin Pediatr Dent 2006;30(4):287-291.

38. Westerman GH, Ellis RW, Latta MA, Powell GL. An in vitro study of enamel surface microhardness following argon laser irradiation and acidulated phosphate fluoride treatment. Pediatr Dent 2003;25(5):497-500.

39. Steiner-Oliveira $C$, Rodrigues $L K$, Lima EB, Nobre-dos-Santos M. Effect of the $\mathrm{CO} 2$ laser combined with fluoridated products on the inhibition of enamel demineralization. J Contemp Dent Pract 2008;9(2):113-121.

40. Apel C, Birker L, Meister J, Weiss C, Gutknecht N. The caries-preventive potential of subablative Er:YAG and Er:YSGG laser radiation in an intraoral model: a pilot study. Photomed Laser Surg 2004;22(4):312-317. [CrossRef]

41. Eversole LR, Rizoiu I, Kimmel AI. Pulpal response to cavity preparation by an erbium, chromium:YSGG laser-powered hydrokinetic system. J Am Dent Assoc 1997;128(8):10991106. 
42. Yazicı AR. Kompozit Rezin Restorasyonlarda İki Farklı Yüzey Pürüzlendirme Yöntemi Olan Asit ve Lazerin Kenar Sızıntısına Etkisinin İn Vitro Olarak İncelenmesi [Doktora Tezi]. Ankara: Hacettepe Üniversitesi; 1999.

43. Usumez $\mathrm{S}$, Orhan $\mathrm{M}$, Usumez $\mathrm{A}$. Laser etching of enamel for direct bonding with an Er,Cr:YSGG hydrokinetic laser system. Am J Orthod Dentofacial Orthop 2002;122(6):649-656. [CrossRef]

44. Gutknecht N, Apel C, Schafer C, Lampert F. Microleakage of composite fillings in $\mathrm{Er}, \mathrm{Cr}$ : YSGG laser-prepared class II cavities. Lasers in Surgery and Medicine 2001;28(4):371-374. [CrossRef]

45. Youssef MN, Youssef FA, SouzaZaroni WC, Turbino ML, Vieira MM. Effect of enamel preparation method on in vitro marginal microleakage of a flowable composite used as pit and fissure sealant. Int $\mathrm{J}$ Paediatr Dent 2006;16(5):342-347. [CrossRef]

46. Moshonov J, Stabholz A, Zyskind D, Sharlin E, Peretz B. Acid-etched and erbium:yttrium aluminium garnet laser-treated enamel for fissure sealants: a comparison of microleakage. Int $\mathrm{J}$ Paediatr Dent 2005;15(3):205-209. [CrossRef]

47. Cehreli SB, Gungor HC, Karabulut E. Er,Cr:YSGG laser pretreatment of primary teeth for bonded fissure sealant application: a quantitative microleakage study. J Adhes Dent 2006;8(6):381-386.

48. Hossain M, Yamada $Y$, Nakamura $Y$, Murakami Y, Tamaki Y, Matsumoto K. A study on surface roughness and microleakage test in cavities prepared by Er:YAG laser irradiation and etched bur cavities. Lasers Med Sci 2003;18(1):25-31. [CrossRef]

49. Gorgul G, Kivanc BH, Maden M, Ulusoy OI, Tinaz AC. Effects of Nd: YAG laser irradiation on the adaptation of composite resins to root dentin. J Contemp Dent Pract 2005;6(4):116-123.

50. Quo BC, Drummond JL, Koerber A, Fadavi S, Punwani I. Glass ionomer microleakage from preparations by an $\mathrm{Er} / \mathrm{YAG}$ laser or a high-speed handpiece. J Dent 2002;30(4):141146. [CrossRef]

51. Ceballos L, Osorio R, Toledano $\mathrm{M}$, Marshall GW. Microleakage of composite restorations after acid or Er-YAG laser cavity treatments. Dent Mater 2001;17(4):340-346. [CrossRef]

52. Aranha AC, Turbino ML, Powell GL, Eduardo Cde P. Assessing microleakage of class $\mathrm{V}$ resin composite restorations after Er:YAG laser and bur preparation. Lasers Surg Med 2005;37(2):172-177. [CrossRef]

53. Delme KI, Deman PJ, De Moor RJ. Microleakage of class $\mathrm{V}$ resin composite restorations after conventional and Er:YAG laser preparation. J Oral Rehabil 2005;32(9):676-685. [CrossRef]

54. Arisu HD, Sadik B, Bala O, Turkoz E. Computer-assisted evaluation of microleakage after apical resection with laser and conventional techniques. Lasers Med Sci 2008;23(4):415-420. [CrossRef]

55. Armengol $\mathrm{V}$, Jean $\mathrm{A}$, Enkel $\mathrm{B}$, Assoumou M, Hamel $\mathrm{H}$. Microleakage of class $\mathrm{V}$ composite restorations following Er:YAG and $\mathrm{Nd}$ :YAP laser irradiation compared to acid-etch: an In vitro study. Lasers Med Sci 2002;17(2):93-100. [CrossRef]

56. Corona SA, Borsatto MC, Pecora JD, De SARRA, Ramos TS, Palma-Dibb RG. Assessing microleakage of different class $\mathrm{V}$ restorations after Er:YAG laser and bur preparation. $\mathrm{J}$ Oral Rehabil 2003;30(10):10081014. [CrossRef] 
57. Roebuck EM, Saunders WP, Whitters CJ. Influence of Erbium:YAG laser energies on the microleakage of Class $\mathrm{V}$ resin-based composite restorations. Am J Dent 2000;13(5):280-284.

58. Ergucu Z, Celik EU, Turkun $M$. Microleakage study of different adhesive systems in Class $\mathrm{V}$ cavities prepared by Er,Cr:YSGG laser and bur preparation. Gen Dent 2007;55(1):27-32.

59. Yamazaki R, Goya $\mathrm{C}, \mathrm{Yu} \mathrm{DG}$, Kimura Y, Matsumoto K. Effects of erbium,chromium:YSGG laser irradiation on root canal walls: a scanning electron microscopic and thermographic study. J Endod 2001;27(1):9-12. [CrossRef]

60. Chen WH. YSGG laser root canal therapy. Dent Today 2002;21(5):7477.

61. Soares F, Varella $\mathrm{CH}$, Pileggi $\mathrm{R}$, Adewumi A, Guelmann M. Impact of Er,Cr:YSGG laser therapy on the cleanliness of the root canal walls of primary teeth. J Endod 2008;34(4):474-477. [CrossRef]

62. Jahan KM, Hossain M, Nakamura $Y$, Yoshishige Y, Kinoshita J, Matsumoto K. An assessment following root canal preparation by Er,Cr: YSGG laser irradiation in straight and curved roots, in vitro. Lasers Med Sci 2006;21(4):229-234. [CrossRef]

63. Schoop U, Barylyak A, Goharkhay K, Beer F, Wernisch J, Georgopoulos A, Sperr W, Moritz A. The impact of an erbium, chromium:yttrium- scandium-gallium-garnet laser with radial-firing tips on endodontic treatment. Lasers Med Sci 2009;24(1):59-65. [CrossRef]

64. Santucci PJ. Dycal versus Nd:YAG laser and Vitrebond for direct pulp capping in permanent teeth. J Clin Laser Med Surg 1999;17(2):69-75.

65. Elliott RD, Roberts MW, Burkes J, Phillips C. Evaluation of the carbon dioxide laser on vital human primary pulp tissue. Pediatr Dent 1999;21(6):327-331.

66. Odabas ME, Bodur H, Baris E, Demir C. Clinical, radiographic, and histopathologic evaluation of $\mathrm{Nd}$ :YAG laser pulpotomy on human primary teeth. J Endod 2007;33(4):415-421. [CrossRef]

67. Kimura $\mathrm{Y}, \mathrm{Yu}$ DG, Fujita A, Yamashita A, Murakami Y, Matsumoto K. Effects of erbium,chromium:YSGG laser irradiation on canine mandibular bone. J Periodontol 2001;72(9):11781182. [CrossRef]

68. Rizoiu I, Kohanghadosh F, Kimmel AI, Eversole LR. Pulpal thermal responses to an erbium,chromium: YSGG pulsed laser hydrokinetic system. Oral Surg Oral Med Oral Pathol Oral Radiol Endod 1998;86(2):220-223. [CrossRef]

69. Genovese MD, Olivi G. Laser in paediatric dentistry: patient acceptance of hard and soft tissue therapy. Eur J Paediatr Dent 2008;9(1):13-17. 